\title{
A Prospective Study of Antibiotic Prescribing Pattern among Pediatrics in a Government District Headquarters Hospital, South India
}

\author{
Haroledpeter P.L. ${ }^{1}$, Sampathkumar Madhusudhan², Thirupathykumaresan P $^{3}$, Keerthiyurenikka $\mathrm{J}^{4}$, \\ Murugakadavul Arumugavignesh ${ }^{4, *}$, Rajasmith Paul McGrath ${ }^{4}$
}

${ }^{1}$ Department of Pharmacy Practice, Arulmigu Kalasalingam College of Pharmacy, Anand Nagar, Krishnankoil, Tamil Nadu, INDIA. ${ }^{2}$ Department of Pharmacy, Faculty of Engineering and Technology, Annamalai University, Chidambaram, Tamil Nadu, INDIA. ${ }^{3}$ Department of Pharmacology, Arulmigu Kalasalingam College of Pharmacy, Anand Nagar, Krishnankoil, Tamil Nadu, INDIA. ${ }^{4}$ Doctor of Pharmacy, Arulmigu Kalasalingam College of Pharmacy, Anand Nagar, Krishnankoil, Tamil Nadu, INDIA.

\begin{abstract}
Objectives: The study aims to know about antibiotic prescribing pattern among pediatric patients admitted in a government headquarters hospital. Methods: This is a prospective observational study involving 159 pediatric patients. It was a six month study conducted between September 2019 and March 2020. Relevant information for analysis was obtained through accessing case sheets of patients. Results: Majority of pediatric patients were children $(54.72 \%)$. There was a male preponderance $(58 \%)$. The total number of antibiotics prescribed was fourteen. Cefotaxime was the most frequently used antibiotic. Majority of prescriptions contain one antibiotic $(47.80 \%)$. Conclusion: This study will promote rational use of antibiotics among patients and health care professionals and thus pave a way to minimize antibiotic resistance.
\end{abstract}

Key words: Pediatrics, Antibiotics, Cefotaxime, Prescription, Rational use, Pharmacoepidemiology.

\section{INTRODUCTION}

Pharmacoepidemiological research is described as the study to estimate the utilization pattern and effect of drugs in any clinical populations and to understand the various therapeutic outcomes like adverse drug reactions, drug effects like drug-drug interactions, medication adherence. ${ }^{1}$ It is the study of drug oriented safety and its effectiveness. Rationalization is the approach of deprescribing inappropriate medications and prescribing the most appropriate correct medication appropriate for the relevant pathologic conditions as per the need of an individual. ${ }^{2}$ Rational usage of drugs is required for an effective treatment to achieve the therapeutic goals and maintain standards as per the established protocol. It was accepted therapeutically in World Health Organization (WHO) conference in the year 1985 in Nairobi as; requirement of the patient needs to meet their own clinical needs, at an affordable cost, for an adequate period of time. ${ }^{3}$ The pediatric prescription contains dosing errors, which is a specific one that needs to be studied and monitored continuously for the benevolence of our pediatric population. ${ }^{4}$ Also there is a need for more judicious prescriptions in order to avoid antibiotic resistance among pediatrics. ${ }^{5}$ This study broadly aims and emphasizes the rational use of drugs especially antibiotics, which has been influenced by age, gender and disease prevalence studies. It would also pave a platform for the researchers to extend further distinct explorative research perspectives of similar studies as well.

\section{MATERIALS AND METHODS}

\section{Data Source}

This is a population-based randomized prospective observational study performed
DOI: 10.5530/ijopp.14.2.23

Address for correspondence: Mr. M Arumugavignesh, IV Pharm D,

Students, Doctor of Pharmacy, Arulmigu Kalasalingam College of Pharmacy, Anand Nagar, Krishnankoil, Tamil Nadu, INDIA. Phone no: +91 8072046740 Email id: m.arumugavignesh20@ gmail.com

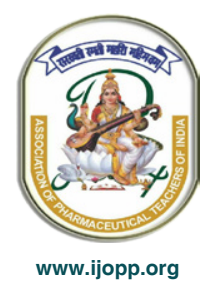


in Virudhunagar Government District Headquarters Hospital, India during the period from September 2019 to March 2020. The case sheets of pediatric inpatients required for this study was collected during ward rounds duly permitted by the authorities of the above-mentioned hospital. The institutional human ethical committee was approved by the member secretary, Human ethical committee, Government headquarters hospital, Virudhunagar district, Tamil Nadu, for permitting us to perform this study and the reference number for which the ethical certificate is given as R.No 110 / HS / GHQH - VNR / SEP 2019.

\section{Data Size}

This work includes one hundred and fifty nine (159) patients, including both male and female pediatric inpatients from various departments like male pediatric, female pediatric, antenatal wards, postnatal wards of Virudhunagar District Headquarters Hospital. Young in-patients with serious illness were excluded from this study. This was a systematic randomized sampling study done by considering the margin of error of $\pm 5 \%$ with a confidence interval of $95 \%$ though the population data was taken accurately enough for the study.

\section{Data Analysis}

The case sheet of every 159 pediatric patients was followed up weekly twice by doctor of pharmacy students of our Institution until patient discharged. The subjective evidence, objective evidence, treatment plan were collected from the random case sheets. The demographical factors like age, gender; disease prevalence and drug treatment care given to the patient's especially antibiotic usage have been considered as important for this work. The data collected were separated in spreadsheets and analyzed for assessment and interpretation.

\section{RESULTS}

From Table 1, it was portrayed that samples were grouped based upon the ages like; Neonates, infants, children and adolescents. Mostly Children are more prone to infections and infectious diseases in recent days but the reason is to obscure in certain clinical conditions. Among the 159 Pediatrics patients in our study, $1.89 \%$ of them were neonates, $22.01 \%$ of them were infants, $54.72 \%$ of them were children and the remaining $21.38 \%$ were adolescents.

Neonates were the least infected among all the pediatric patients whom we have included for our study. More Prevalence of either infectious or non-infectious diseases might be due to the lack of cleanliness, slapdash care or
Table 1: Classification of Institutionalized Pediatrics

Patients Based on Age.

Class

Frequency (N)

Percentage (\%)

Neonates

3

1.89

Infants

35

22.01

Children

87

54.72

Adolescent

34

21.38

Total

159

100

Table 2: Gender wise Classification of Institutionalized

Pediatrics Patients.

\begin{tabular}{ccc} 
Gender & Frequency (N) & Percentage (\%) \\
\hline Male & 92 & 58 \\
Female & 67 & 42 \\
Total & 159 & 100 \\
\hline
\end{tabular}

malnourishment nutrition to Pediatric population. Yet to extend our study to find out the exact reason for the occurrence of diseases among pediatric patients from rural and urban areas has to carry out in the days to come in future.

Out of all inclusive 159 pediatric patients, 92 were male pediatric patients and 67 were female patients. From the above Table 2 , it was depicted that male young patients were predominantly affected with diseases than feminine gender.

It clearly emphasizes that $58 \%$ of male patients were majorly affected than the female pediatric individuals that is of $42 \%$. This hierarchical classification of the samples into male and female gender pediatric patients helps researchers in further explorative study in finding the valid reasons for the disease prevalence, which may also help the physicians to diagnose still more efficiently and to provide the right choice of drugs with proper dosing intervals and dosage forms for a specific duration of time.

Antibiotic is defined as an antibacterial medicine (such as penicillin, cephalosporin and ciprofloxacin) that is used to treat or prevent infections by killing or inhibiting the growth of bacteria in or on the body. It can be either administered orally, topically, or by injection. Antibiotics isolated from cultures of certain microorganisms (such as fungi) are of semi-synthetic or synthetic origin. ${ }^{6}$ The list of antibiotics used in pediatric prescriptions of this study is given below in Table 3 .

From the Table 3, it was clearly pointed out that the total number of antibiotics used were only 14 in category of all the total 159 prescriptions. Among all the antibiotics prescribed by physicians cefotaxime, 
Table 3: Antibiotic Usage in Institutionalized Pediatric Prescriptions.

\begin{tabular}{cc}
\hline Antibiotics & Frequency \\
\hline Cefotaxime & 65 \\
Ceftriaxone & 38 \\
Ampicillin & 33 \\
Amikacin & 32 \\
Gentamicin & 13 \\
Doxycycline & 8 \\
Metronidazole & 7 \\
Ciprofloxacin & 7 \\
Cloxacillin & 6 \\
Kanamycin & 3 \\
Amoxicillin & 2 \\
Cotrimoxazole & 2 \\
Piperacillin/Tazobactam & 1 \\
Tobramycin & 1 \\
\hline
\end{tabular}

which is a third generation cephalosporin antibiotic was the most frequently prescribed medication i.e. 65 in number in this prospective study. On comparing with the recent survey taken by WHO in Mongolia about the increased non-prescribed antibiotic usage, $42.3 \%$ cases were existed. Recommendation and familiarity about the antibiotics might lead to non-prescribed antibiotic usage/self-medication from pharmacies. ${ }^{7}$ From further assessment, it's clear that at least each prescription had 1 mean antibiotic usage.

In this study we found that overuse of antibiotics among pediatric prescriptions. At one instance definitely superbugs develop and are resistant to most of the antibiotics and other medications commonly used to treat the infections they cause. According to the Cochrane database analysis of randomized controlled trials demonstrated that prescribing of too many antibiotics might increase in; the adverse effects, affordability of healthcare services and causing antibiotic drug resistance. ${ }^{8}$ Overuse of antibiotics instigate drug resistance and may culminate to increase in detrimental complications. Then it would be a chaotic situation for the physician to treat the patient with lifesaving antibiotics if infected with hospital acquired superbugs. Unwanted prescribing of antimicrobials might cause adverse effects which require additional treatment rather than specific rational therapy. Undesirable treatment by antibiotics over viral infections, common respiratory infections should be reduced to provide rationalized therapy for pediatric patients. ${ }^{9}$

In our study, with respect to rationalizing the pediatric prescription of drugs, the prescriptions without antibiotics were only $11.95 \%$, remaining 76 pediatric
Table 4: Prescribing Pattern of Antibiotics in Pediatric

Patient Prescriptions.

\begin{tabular}{|ccc}
\hline Prescription Indicator & $\begin{array}{c}\text { Frequency } \\
\text { (N) }\end{array}$ & $\begin{array}{c}\text { Percentage } \\
\text { (\%) }\end{array}$ \\
\hline $\begin{array}{c}\text { No. of prescriptions without } \\
\text { antibiotics }\end{array}$ & 19 & 11.95 \\
$\begin{array}{c}\text { No. of prescriptions with } 1 \\
\text { antibiotic }\end{array}$ & 76 & 47.8 \\
$\begin{array}{c}\text { No. of prescriptions with 2 } \\
\quad \text { antibiotics }\end{array}$ & 51 & 32.08 \\
$\begin{array}{c}\text { No. of prescriptions with 3 } \\
\quad \text { antibiotics }\end{array}$ & 12 & 7.55 \\
$\begin{array}{c}\text { No. of prescriptions with more } \\
\text { than } 3 \text { antibiotics }\end{array}$ & 1 & 0.63 \\
\hline
\end{tabular}

prescriptions had at least 1 antibiotic drug in each. Pediatric prescriptions with 2 and 3 antibiotics in each prescription were 51 and 12 respectively. During the study period only one prescription remained with more than 3 antibiotics prescribed by the physician. The relevant details about the antibiotic usage in the prescriptions were tabulated in Table 4.

\section{DISCUSSION}

We had collected 159 pediatric inpatients prescriptions for an observational prospective study on rational usage analysis of medicines throughout the mentioned period regularly. The sample taken for study had been grouped and classified by using demographic data; age and gender wise to make the work precise and comfortable. The information data regarding the demographics was tabulated in Table 1 and 2. Pediatric population is more prone to infections easily, due to improper sanitation and nutritional procedure. It should be educated widely among parents, caretaker of young children. The most common illness experienced by children include common cold, diarrhea, tonsillitis, ear infections, tooth decay, conjunctivitis, several congenital malformations. ${ }^{10}$ According to the $\mathrm{WHO}$, pneumonia and diarrhea are among the leading causes of deaths in children under 5 years of age. ${ }^{11}$

The young inpatients of our study reported with various infectious and non-infectious diseases like upper and lower respiratory infections, gastrointestinal, urinary and nervous abnormalities like seizures. The rural population considered in this study was affected with malnutrition, lack of equipping themselves with general requirements to live in nifty environment for healthy lifestyle. ${ }^{12}$ Pediatric population gets easily affected by fever, upper and lower respiratory tract infections. ${ }^{13}$

The prescription of pediatric patients of our study mostly had cephalosporin antibiotics (cefotaxime and 
ceftriaxone) $(n=103)$ except 19 prescriptions those are without any antibiotic drug. This is similar to the prescription study by Venkateswaramurthy N. et al. ${ }^{14}$ Antibiotics leads to allergic condition like rash which is difficult to identify because it might be due to some other trigger factors in pediatrics occurs generally. Cephalosporin antibiotics like cefotaxime may cause cross reactivity, the clinical condition which occurs during alternate antibiotic suggested by the physician. ${ }^{15}$ However The American Academy of Pediatrics, evidence-based guidelines upheld the use of cephalosporin antibiotics for patients with reported allergies to penicillin, for the treatment of acute bacterial sinusitis and acute otitis media. ${ }^{16}$ The true cause, indication of the drug related side effects are rarely considered, if so it might lead to overuse of drugs. ${ }^{17}$ Antibiotic usage in these pediatric inpatients as given in Table 4 describes the proper prescribed amount of antibiotics of this study. Among 14 antibiotics used in pediatrics, 4 were from penicillin derivatives (ampicillin, amoxicillin, cloxacillin, piperacillintazobactam), 4 were from aminoglycosides (amikacin, gentamicin, kanamycin, tobramycin), 2 were from cephalosporin class (cefotaxime, ceftriaxone), one from fluroquinolone (ciprofloxacin), one from tetracycline (doxycycline), one from antiprotozoal (metronidazole) and one from sulphonamide (cotrimaxazole).

Proper prescription guidelines for the usage of antibiotics should be given by proper packaging and labeling requirements. ${ }^{18}$ This can be further facilitated by antibiotic stewardship program. One study notes the significant reduce in DDD (Defined Daily Dose) of many antibiotics after such stewardship program. ${ }^{19}$ Recently CDSCO has prepared a new schedule for prohibiting over the counter (OTC) use of 91 antibiotics with red color Rx labeling not to be sold without physician's prescriptions. These antibiotics were separately listed as Schedule H1, which might lead to proper utilization of antibiotics in future. ${ }^{20}$ Moreover restriction of usage of some antibacterial agents is a desirable method to decrease antibiotic consumption and a way to minimize expenditure and helps to prevent emergence of resistant microbes in hospitals. ${ }^{21}$

Here all the patients were provided proper therapy and majority cases had shown a healthy physician-patient affiliation and good compliance in therapy. Most drugs were prescribed in generic name. This will promote the habit of generic prescription among other hospital settings also. The particular causes for occurrence of various diseases among these rural areas is yet to be studied by us in future to promote a rational therapy along with proper patient education to all. The patient counseling and educating drug information should be given by clinical pharmacists to indulge the treatment inpatients free from medication errors and awareness about adverse drug events to reduce the fear in patients. ${ }^{22}$

\section{CONCLUSION}

This population based study was performed in Virudhunagar Government Head Quarters Hospital including 159 inpatients of pediatrics underlines the importance of rationalization of medications especially antibiotics. Rational use of drugs is an important concept to be followed in all the prescriptions prescribed by physicians. The rationalization which projects the important key ideas about the drug utilization studies, drug prevalence studies based on condition, evidence based medicine and other related ones. Antibiotics should be wisely implemented and used in treatment which on over expansive use in prescriptions might develop resistance to certain drugs which tends for alternative approaches. Further studies are required to improve the rationalization criterion in prescriptions by exploring knowledge with huge approach towards antibiotics.

\section{ACKNOWLEDGEMENT}

We are indebted to express our gratitude and sincere thanks to the member secretary of Virudhunagar government headquarters hospital for providing us human ethical committee certificate. We also express our whole hearted thanks to all physicians, nurses and staff members of the concern hospital for being the chief provider of medical care and management for the patient and granting access to the patient's medical records.

\section{CONFLICT OF INTEREST}

The authors declare no conflict of interest.

\section{ABBREVIATIONS}

WHO: World Health Organization; DDD: Defined Daily Dose; OTC: Over the Counter drugs; CDSCO: The Central Drugs Standard Control Organization.

\section{SUMMARY}

Pharmacoepidemiological research is described as the study to estimate the utilization pattern and effect of drugs in any clinical populations and to understand the various therapeutic outcomes like adverse drug reactions, drug effects like drug-drug interactions, medication adherence. This study broadly aims and emphasizes the rational use of drugs especially antibiotics, which has been influenced by age, gender and disease prevalence studies. Antibiotics should be wisely administered and the overuse of the same will lead to antibiotic resistance. 


\section{REFERENCES}

1. Furu K, Wettermark B, Andersen M, Martikainen JE, Almarsdottir AB, Sørensen HT. The Nordic countries as a cohort for pharmacoepidemiological research. Basic and Clinical Pharmacology and Toxicology. 2010;106(2):86-94.

2. Murni IK, Duke T, Kinney S, Daley AJ, Soenarto Y. Reducing hospital-acquired infections and improving the rational use of antibiotics in a developing country: An effectiveness study. Archives of Disease in Childhood. 2015;100(5):454-9.

3. Aravamuthan A, Arputhavanan M, Subramaniam K. Assessment of current prescribing practices using World Health Organization core drug use and complementary indicators in selected rural community pharmacies in Southern India. Journal of Pharmaceutical Policy and Practice. 2017;10(1):1.

4. Cimino MA, Kirschbaum MS, Brodsky L, Shaha SH. Child Health Accountability Initiative: Assessing medication prescribing errors in pediatric intensive care units. Pediatric Critical Care Medicine. 2004;5(2):124-32.

5. Finkelstein JA, Stille C, Nordin J, Davis R, Raebel MA, Roblin D, et al. Reduction in antibiotic use among US children, 1996-2000. Pediatrics. 2003;112(3):620-7.

6. Kümmerer K. Significance of antibiotics in the environment. Journal of Antimicrobial Chemotherapy. 2003;52(1):5-7.

7. Carlet J, Jarlier V, Harbarth S, Voss A, Goossens H, Pittet D. Ready for a world without antibiotics? The pensières antibiotic resistance call to action. 2012.

8. McCullough AR, Parekh S, Rathbone J, DelMar CB, Hoffmann TC. A systematic review of the public's knowledge and beliefs about antibiotic resistance. Journal of Antimicrobial Chemotherapy. 2016;71(1):27-33.

9. Watson RL, Dowell SF, Jayaraman M, Keyserling H, Kolczak M, Schwartz B. Antimicrobial use for pediatric upper respiratory infections: Reported practice, actual practice and parent beliefs. Pediatrics. 1999;104(6):1251-7.

10. Potocki M, Goette J, Szucs TD, Nadal D. Prospective survey of antibiotic utilization in pediatric hospitalized patients to identify targets for improvement of prescription. Infection. 2003;31(6):398-403.
11. Hoan LT, Chuc NT, Ottosson E, Allebeck P. Drug use among children under 5 with respiratory illness and/or diarrhoea in a rural district of Vietnam. Pharmacoepidemiol Drug Saf. 2009;18(6):448-53.

12. Jeyaseelan L, Lakshman M. Risk factors for malnutrition in south Indian children. Journal of Biosocial Science. 1997;29(1):93-100.

13. Choi EH, Lee HJ, Kim SJ, Eun BW, Kim NH, Lee JA, et al. The association of newly identified respiratory viruses with lower respiratory tract infections in Korean children, 2000-2005. Clinical Infectious Diseases. 2006;43(5):585-92.

14. Neha P, Shreya S, Pratik A, Anand A. Prescription auditing and drug utilization pattern in indoor patients of pediatrics department. Int J Cur Res Rev. 2016;8(23):39.

15. Miranda A, Blanca M, Vega JM, Moreno F, Carmona MJ, García JJ, Segurado E, et al. Cross-reactivity between a penicillin and a cephalosporin with the same side chain. Journal of Allergy and Clinical Immunology. 1996;98(3):671-7.

16. Pichichero ME. A review of evidence supporting the American Academy of Pediatrics recommendation for prescribing cephalosporin antibiotics for penicillin-allergic patients. Pediatrics. 2005;115(4):1048-57.

17. Alumran A, Hurst C, Hou XY. Antibiotics overuse in children with upper respiratory tract infections in Saudi Arabia: Risk factors and potential interventions. Clinical Medicine and Diagnostics. 2011;1(1):8-16.

18. Pandolfini C, Bonati M. A literature review on off-label drug use in children. European Journal of Pediatrics. 2005;164(9):552-8.

19. Jayakar B, Aleykutty NA, Mathews SM. Changes in daily defined doses (DDD) of antibiotics after restricted use in medical inpatients. Journal of Applied Pharmaceutical Science. 2011;1(6):22.

20. Laxminarayan R, Chaudhury RR. Antibiotic resistance in India: drivers and opportunities for action. PLoS Medicine. 2016;13(3):e1001974.

21. Vlahovic-Palcevski V, Morovic M, Palcevski G. Antibiotic utilization at the university hospital after introducing an antibiotic policy. European Journal of Clinical Pharmacology. 2000;56(1):97-101.

22. Kotwani A, Wattal C, Joshi PC, Holloway K. Irrational use of antibiotics and role of the pharmacist: An insight from a qualitative study in New Delhi, India. Journal of Clinical Pharmacy and Therapeutics. 2012;37(3):308-12. 